\title{
Lindnera rhizosphaerae sp. nov., a yeast species isolated from rhizospheric soil
}

Correspondence

M. Cecilia Mestre

mcmestre@crub.uncoma.edu.ar

\author{
M. Cecilia Mestre, ${ }^{1}$ Carlos A. Rosa ${ }^{2}$ and Sonia B. Fontenla ${ }^{1}$
}

\begin{abstract}
${ }^{1}$ Laboratorio de Microbiología Aplicada y Biotecnología, Centro Regional Universitario Bariloche (CRUB), INIBIOMA (Universidad Nacional del Comahue-CONICET), Quintral 1250, Bariloche (8400), Río Negro, Argentina

${ }^{2}$ Departamento de Microbiologia - ICB, C.P. 486, Universidade Federal de Minas Gerais, Belo Horizonte, MG 31270-901, Brazil
\end{abstract}

\begin{abstract}
Two strains of a novel yeast species were isolated from ectomycorrhizal Nothofagus pumilio rhizospheric soil in a native forest of Patagonia, Argentina. Analysis of the D1/D2 large-subunit rRNA gene sequences indicated that the novel species belongs to the recently described genus Lindnera. The name Lindnera rhizosphaerae sp. nov. is proposed to accommodate these isolates, and the type strain is CRUB $1796^{\top}\left(=\mathrm{CBS} 11400^{\top}=\mathrm{JCM} 16499^{\top}\right)$.
\end{abstract}

The genus Lindnera was recently proposed by Kurtzman et al. (2008) based on analyses of nucleotide sequence divergence in the genes coding for large and small-subunit rRNAs and for translation elongation factor- $1 \alpha$. This new genus included coenzyme Q-7-forming species, previously assigned to the genera Pichia and Williopsis. Species of the Lindnera clade differ considerably in ascospore morphology (spherical, hatshaped or saturn-shaped), and the clade includes both hetero- and homothallic species. Species belonging to the genus Lindnera ferment glucose and assimilate a variety of sugars, polyols and other carbon sources but fail to assimilate methanol and hexadecane (Kurtzman et al., 2008). A proposal has been presented to rename this genus 'Cyberlindnera' (Minter, 2009) because Lindnera is a homonym of a plant genus. Pending acceptance of this proposal, the name Lindnera is used provisionally.

During our surveys on the yeast community associated with Nothofagus pumilio (Fagaceae) rhizospheric soil from native forests of Argentinean Patagonia, two glucosefermenting yeast isolates were obtained which, based on growth characteristics, were assigned to the genus Lindnera (Kurtzman et al., 2008). Analysis of the D1/D2 variable domain of the large-subunit rRNA gene indicated that these strains represent a distinct species phylogenetically and their closest relative is Lindnera rhodanensis. The name Lindnera rhizosphaerae sp. nov. is proposed to accommodate these strains, given their occurrence in rhizospheric soil.

Both strains were isolated from a rhizospheric soil fraction of a native forest dominated by ectomycorrhizal Notho-

The GenBank/EMBL/DDBJ accession number for the 26S rRNA gene sequences of strains CRUB $1796^{\top}$ and CRUB 1797 are G0891688 and G0891689, respectively.

A supplementary table is available with the online version of this paper. fagus pumilio adult trees on the south-east slope of Cerro Otto in San Carlos de Bariloche (Nahuel Huapi National Park), Argentina, in summer 2008. Two N. pumilio adult trees were randomly selected at a distance of more than $15 \mathrm{~m}$ apart. Strain CRUB $1796^{\mathrm{T}}$ (also named OR54) was isolated from a tree in the central forest area with an herbaceous understory. Strain CRUB 1797 (OR47) was isolated from a tree located on the edge of the forest next to a Chusquea culeou Desv. (Poaceae) area. Three soil cores (subsamples) from each tree were collected aseptically at $60 \mathrm{~cm}$ from the trunk, equidistantly. The superficial layer $(2 \mathrm{~cm})$ had previously been removed. Each subsample was processed individually in the laboratory. Root fragments were gently shaken to recover the rhizospheric fraction, which was suspended in a sterile $0.9 \%$ $\mathrm{NaCl}$ solution to a final concentration of $1: 25(\mathrm{w} / \mathrm{v})$ and shaken at 250 r.p.m. for $30 \mathrm{~min}$. One hundred microlitres of this suspension was spread on plates containing MYP agar (malt extract $0.7 \%$, yeast extract $0.05 \%$, peptone-soytone $0.25 \%$, agar $1.5 \%$ ) supplemented with $25 \mu \mathrm{g}$ Rose Bengal $\mathrm{ml}^{-1}$ and $200 \mu \mathrm{g}$ chloramphenicol $\mathrm{ml}^{-1}$ and incubated at $20{ }^{\circ} \mathrm{C}$ (Mestre et al., 2009).

Physiological characterization of isolates was performed in solid media following standard methods (Yarrow, 1998). DNA extraction was performed using a classical phenol/ chloroform/isoamyl alchohol technique adapted from Raeder \& Broda (1985). The D1/D2 domain at the 5' end of the large subunit rRNA gene was amplified using primers NL-1 (5'-GCATATCAATAAGCGGAGGAAAAG) and NL-4 (5'-GGTCCGTGTTTCAAGACGG). Amplification was performed for 35 PCR cycles with annealing at $54{ }^{\circ} \mathrm{C}$, extension at $72{ }^{\circ} \mathrm{C}$ for $20 \mathrm{~s}$, and denaturation at $94{ }^{\circ} \mathrm{C}$ for $15 \mathrm{~s}$. Fragment amplification and size were confirmed by $1.5 \%$ agarose gel electrophoresis and gels were stained with ethidium bromide. Sequencing of amplicons was carried out using an ET Dynamic 
Terminator kit in a MegaBACE 1000/Automated 96 Capillary DNA sequencer (GE Healthcare). Comparisons with sequences from the international GenBank database (http://www.ncbi.nlm.nih.gov/) were done using BLASTN search. Sequence alignment and neighbour-joining tree reconstruction (based on 1000 bootstrap iterations) was performed with MEGA version 4 (Tamura et al., 2007).

Sequence comparisons indicated that the novel species belongs to the genus Lindnera and is closely related to $L$. rhodanensis, from which it differs by 39 substitutions in the D1/D2 large-subunit rRNA gene sequence. The sequences obtained from both strains were identical. Phylogenetic placement of Lindnera rhizosphaerae sp. nov. is shown in Fig. 1.

The Lindnera clade phylogram branching pattern revealed the association of species with similar isolation substrates. Species isolated from insect substrates grouped together; all of them share the capacity to assimilate sucrose, maltose, trehalose, glucitol, mannitol, citrate and, with one exception, melezitose (Table 1). Soil-associated species within the Lindnera clade grouped together in the phylogenetic tree, and they lack the ability to assimilate maltose, trehalose and melezitose (except Candida vartiovaarae). Lindnera rhizosphaerae sp. nov. and other species isolated from substrates related to rotting bark, trees, orchard environments and plants form a diverse group basal to the other two with variable physiological characteristics. Many species of the genus Lindnera seem to be related to decomposing processes (for isolation substrates of Lindnera clade strains see Supplementary Table S1 available in IJSEM Online).

Lindnera rhizosphaerae sp. nov. was isolated from the rhizosphere of Nothofagus ectomycorrhizal roots. The rhizosphere is a narrow zone of soil extending for a few millimetres from the plant root (and ectomycorrhizal roots) surface into the surrounding soil. This soil fraction is influenced by an interconnected network of roots and fungi. Nothofagus trees present high ectomycorrhizal infection values (Diehl et al., 2003). Plant root exudates and fungal metabolites may select specific microbial populations (Botha, 2006; Andrews \& Harris, 2000), and Lindnera rhizosphaerae sp. nov. is part of the mycorrhizospheric community associated with Nothofagus trees.

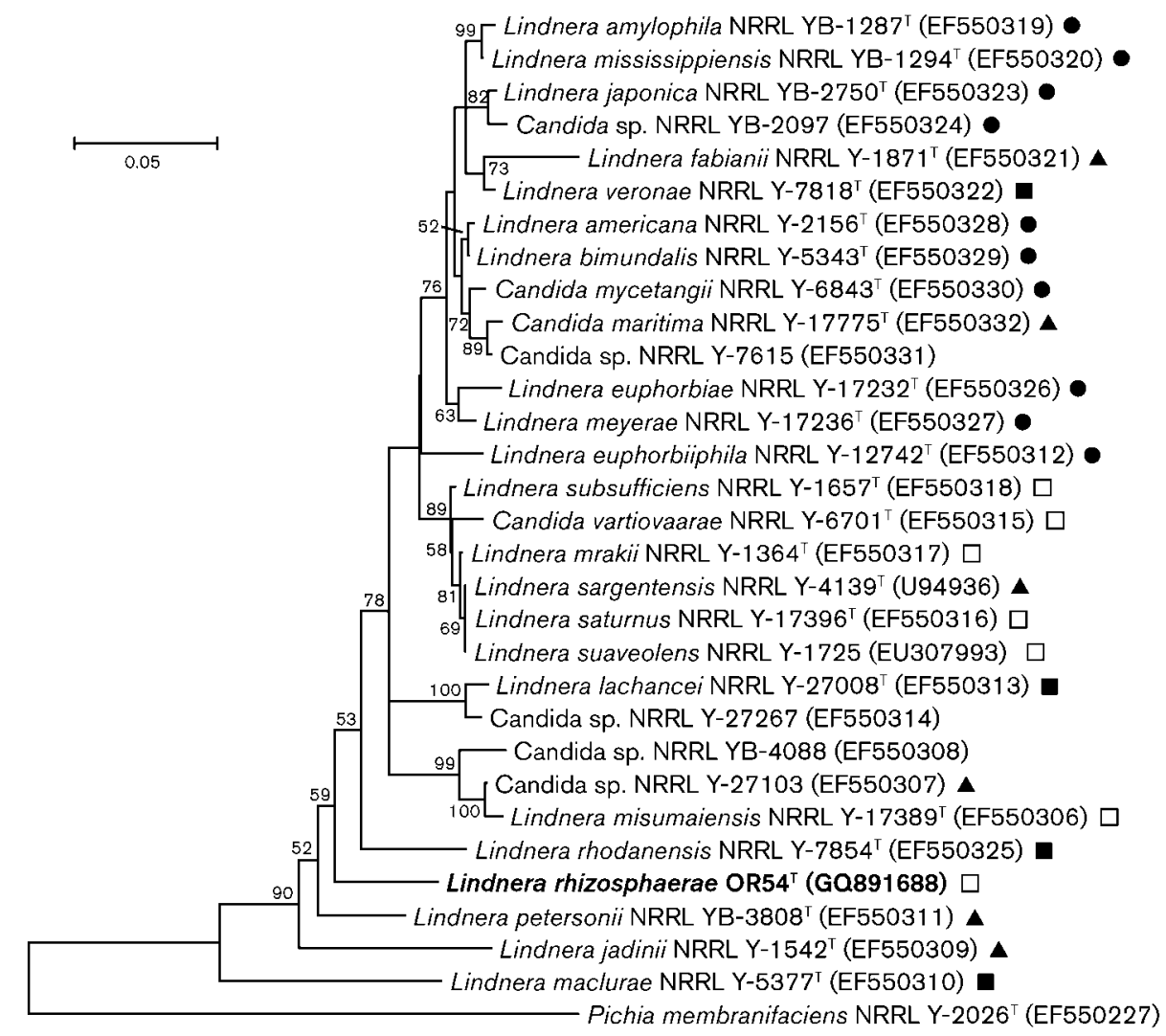

Fig. 1. Lindnera clade. Neighbour-joining phylogram based on the D1/D2 divergent domains of the large-subunit rRNA gene sequence of Lindnera rhizosphaerae sp. nov. and its closest relatives. The consensus tree was rooted with Pichia membranifaciens NRRL Y-2026 ${ }^{\top}$. Percentage bootstrap values were obtained from 1000 iterations (model used: maximum composite likelihood; missing data: complete deletion). Isolation substrate: $\boldsymbol{0}$, insect; $\square$, soil; $\mathbf{\square}$, plant; $\boldsymbol{\Delta}$, others (man, equipment, beer). Strains without data on substrate isolation are unmarked. Bar, 0.05 substitutions per nucleotide position. 
Table 1. Physiological characteristics of members of the Lindnera clade

All data from Kurtzman (1998) and CBS web page (http://www.cbs.knaw.nl/). No available data for strains Candida sp. YB-2097, Candida sp. Y7615, Candida sp. YB-4088 and Candida sp. Y-27267. Gal, D-galactose; Sor, L-sorbose; Ara, L-arabinose; Rham, L-rhamnose; Suc, sucrose; Mal, maltose; Tre, trehalose; Raf, raffinose; Mele, melezitose; Starch, soluble starch; Glucy, D-glucitol; Mann, mannitol; Cit, citrate; $\mathrm{NO}_{3}$, nitrate; $\mathrm{NO}_{2}$, nitrite; + , positive; - , negative; w, weakly positive; $\mathrm{d}$, delayed.

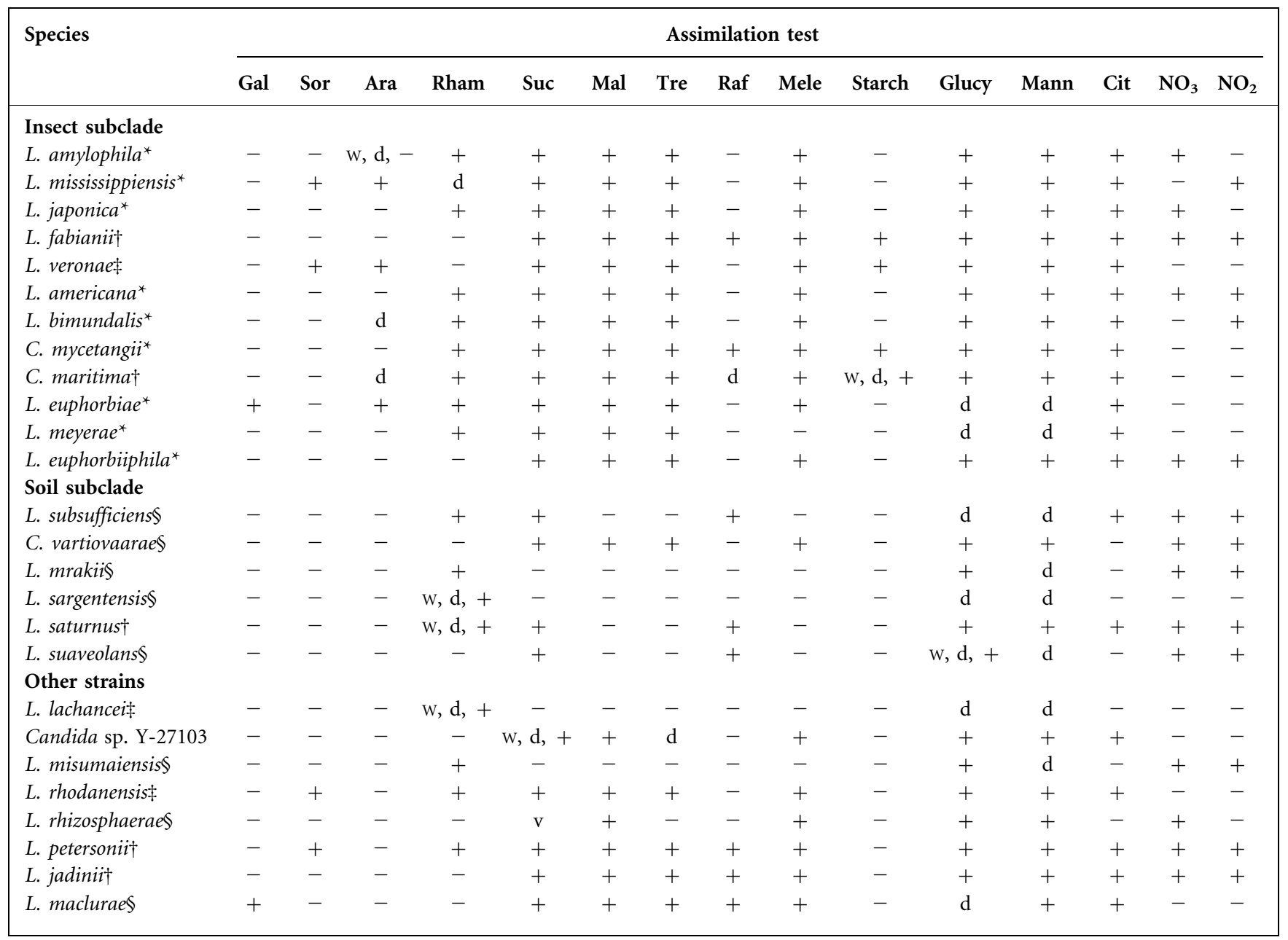

${ }^{\star}$ Insect.

†Others.

$\ddagger$ Plant.

§Soil.

\section{Latin diagnosis of Lindnera rhizosphaerae Mestre, Rosa et Fontenla sp. nov.}

Cellulae vegetativae globosae aut ovoidae. Pseudomycelium nec mycelium nulla. Glauca colonia, marginis integrae. Ascosporae per transformationem ascorum formantur. Asci continentes 4 ascosporas petasiformes et rumpentur. Post dies duos glucosum fermentantur at non maltosum, galactosum, raffinosum, lactosum, sucrosum, nec trehalosum. Glucosum, maltosum, melezitosum, D-xylosum, ethanolum, glycerolum, mannitolum, glucitolum, salicinum, acidum lacticum, acetonum, ethyl acetas, iso-propanol assimilantur, at non galactosum, L-sorbosum, trehalosum, lactosum, melibiosum, raffinosum, amylum solubile, L-arabinosum, D-arabinosum, D-ribosum, L-rhamnosum, erythritolum, ribitolum, galactitolum, acidum succinicum, acidum citricum, mesoinositolum, methanolum, hexadecanum, glucosaminum, xylitolum, acidum gluconicum nec $N$-acetylglucosaminum. Cellobiosum, inulinum et sucrosum asimilantur variabile. Lysinum et natrium nitricum (variabile) assimilantur at non natrium nitrosum. Non augmentum in $30{ }^{\circ} \mathrm{C}$. CRUB $1796^{\mathrm{T}}$ $\left(=\mathrm{CBS} 11400^{\mathrm{T}}=\mathrm{JCM} 16499^{\mathrm{T}}\right)$ species typica est.

\section{Description of Lindnera rhizosphaerae Mestre, Rosa \& Fontenla sp. nov.}

Lindnera rhizosphaerae (rhi.zo.sphae' rae. Gr. n. rhiza root; Gr. n. sphaira (Latin transliteration sphaera) ball, sphere; N.L. n. rhizosphaera the rhizosphere; N.L. gen. n. rhizosphaerae from the sphere of the root). 


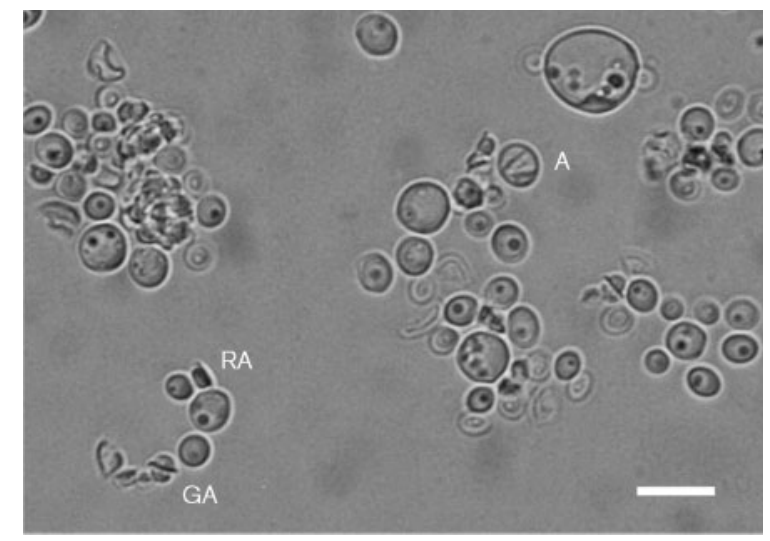

Fig. 2. Micrograph showing cells of strain CRUB $1796^{\top}$ on $5 \%$ malt extract agar after 1 week at $20{ }^{\circ} \mathrm{C}$. RA, released hat-shaped spore; GA, grouped spores; A, asci. Bar, $5 \mu \mathrm{m}$.

\section{Morphology}

Yeast cells after 3 days on $5 \%$ malt extract agar $(5 \%$ malt extract, w/v; $1.5 \%$ agar, w/v) are spheroidal to ovoidal $(4.2-5.8 \times 3.3-5.0 \mu \mathrm{m})$ with multilateral budding. Colonies are white with smooth and glistening surfaces and entire margins. Mycelium is not formed on any of the culture media tested.

Spherical asci are formed by conjugation between two cells. The species is homothallic. Ascospore formation is observed after 5 days on $5 \%$ malt extract agar at $20{ }^{\circ} \mathrm{C}$. Four hat-shaped ascospores can be seen on early stage cultures, (Fig. 2). Ascospores are released and remain together forming groups or chains.

\section{Physiology}

Growth at $30{ }^{\circ} \mathrm{C}$ is negative. Glucose fermentation is observed after $48 \mathrm{~h}$ at $20{ }^{\circ} \mathrm{C}$; maltose, galactose, raffinose, lactose, sucrose and trehalose fermentation is negative. Assimilates the following compounds at $20{ }^{\circ} \mathrm{C}$ : glucose, maltose, melezitose, D-xylose, ethanol, glycerol, D-mannitol, D-glucitol, salicilin, lactic acid, acetone, ethyl acetate, 2propanol and lysine. Does not assimilate the following compounds at $20{ }^{\circ} \mathrm{C}$ : galactose, L-sorbose, trehalose, lactose, melibiose, raffinose, soluble starch, L-arabinose, D-arabinose, D-ribose, L-rhamnose, erythritol, ribitol, galactitol, succinic acid, citric acid, myo-inositol, methanol, hexadecane, glucosamine, xylitol, gluconic acid, $\mathrm{N}$-acetylglucosamine or nitrite. Assimilation of cellobiose, inulin, sucrose and nitrate at $20{ }^{\circ} \mathrm{C}$ is variable. Growth is positive on amino-acid-free YNB and negative on $10 \% \mathrm{NaCl}$ or
$50 \%$ glucose media. Starch-like compounds are not produced. Acid production is weakly positive. Tolerance of $1 \%$ acetic acid and $0.01 \%$ cycloheximide is negative.

Strains were isolated from a Nothofagus pumilio forest (at $41^{\circ} 8^{\prime} 45^{\prime \prime} \mathrm{S} 71^{\circ} 21^{\prime} 38^{\prime \prime} \mathrm{W}$ ) and have been deposited at the Centro Regional Universitario Bariloche (CRUB), Bariloche, Argentina. The type strain is CRUB $1796^{\mathrm{T}}(=\mathrm{CBS}$ $\left.11400^{\mathrm{T}}=\mathrm{JCM} 16499^{\mathrm{T}}\right)$.

\section{ACKNOWLEDGEMENTS}

We thank the authorities of Administración de Parques Nacionales (Argentina) for their courtesy and cooperation. This work was supported by project UNComahue (B143) and FONCyT project PICT04-22200. Bilateral cooperation between Argentina and Brazil was supported by CAPES-MINCyT agreement (BR 06/011) and Conselho Nacional de Desenvolvimento Cientifico e Tecnologico (PROSUL/CNPq, process number 490430/2008-2), Brazil. M.C. M. was supported by ANPCyT PhD grant. The authors wish to thank Dr D. Libkind on his kind reviews of the manuscript.

\section{REFERENCES}

Andrews, J. H. \& Harris, R. F. (2000). The ecology and biogeography of microorganisms on plant surfaces. Annu Rev Phytopathol 38, 145180.

Botha, A. (2006). Yeasts in soil. In Biodiversity and Ecophysiology of Yeasts, pp. 221-240. Edited by C. A. Rosa \& G. Péter. Berlin: Springer.

Diehl, P., Mazzarino, M. J., Funes, F., Fontenla, S., Gobbi, M. \& Ferrari, J. (2003). Nutrient conservation strategies in native AndeanPatagonian forests. J Veg Sci 14, 63-70.

Kurtzman, C. P. (1998). Pichia E.C. Hansen emend. Kurtzman. In The Yeasts, a Taxonomic Study, 4th edn, pp. 273-352. Edited by C. P. Kurtzman \& J. W. Fell. Amsterdam: Elsevier.

Kurtzman, C. P., Robnett, C. J. \& Basehoar-Powers, E. (2008). Phylogenetic relationships among species of Pichia, Issatchenkia and Williopsis determined from multigene sequence analysis, and the proposal of Barnettozyma gen. nov., Lindnera gen. nov. and Wickerhamomyces gen. nov. FEM Yeast Res 8, 939-954.

Mestre, M. C., Libkind, D. \& Fontenla, S. (2009). Comparación de condiciones de cultivo para el aislamiento y recuento simultáneo de levaduras de suelos de bosques nativos de Nothofagus spp. (Fagaceae) de la Patagonia Argentina. Bol Soc Argent Bot 44, 229-238.

Minter, D. W. (2009). Cyberlindnera, a replacement name for Lindnera Kurtzman et al., nom. illegit. Mycotaxon 110, 473-476.

Raeder, U. \& Broda, P. (1985). Rapid preparation of DNA from filamentous fungi. Lett Appl Microbiol 1, 17-20.

Tamura, K., Dudley, J., Nei, M. \& Kumar, S. (2007). MEGA4: molecular evolutionary genetics analysis (MEGA) software version 4.0. Mol Biol Evol 24, 1596-1599.

Yarrow, D. (1998). Methods for the isolation, maintenance and identification of yeasts. In The Yeasts, a Taxonomic Study, 4th edn, pp. 77-100. Edited by C. P. Kurtzman \& J. W. Fell. Amsterdam: Elsevier. 